\title{
Towards an understanding of neuroscience for science educators
}

\author{
Mary Oliver
}

\begin{abstract}
Advances in neuroscience have brought new insights to the development of cognitive functions. These data are of considerable interest to educators concerned with how students learn. This review documents some of the recent findings in neuroscience, which is richer in describing cognitive functions than affective aspects of learning. A brief overview is presented here of the techniques used to generate data from imaging and how these findings have the possibility to inform educators. There are implications for considering the impact of neuroscience at all levels of education - from the classroom teacher and practitioner to policy. This relatively new cross-disciplinary area of research implies a need for educators and scientists to engage with each other. What questions are emerging through such dialogues between educators and scientists are likely to shed light on, for example, reward, motivation, working memory, learning difficulties, bilingualism and child development. The sciences of learning are entering a new paradigm.
\end{abstract}

Keywords: neuroscience; research; teaching; professional learning; pre-service education

hp://www.tandfonline.com/loi/rsse20

Available online: 07 Sep 2011

To cite this article: Mary Oliver (2011): Towards an understanding of neuroscience for science educators, Studies in Science Education, 47(2), 211-235.

DOI: http://dx.doi.org/10.1080/03057267.2011.604478 


\section{Introduction}

In 1848, an explosion caused a large metal rod to enter through the cheek of Phineas Gage. As it exited his skull, Gage survived and recovered from the accident, unable to work again except as a circus act having sustained permanent damage to his frontal cortex causing his physician to record, 'he was no longer Gage'(O' Driscoll \& Leach, 1998). It is perhaps evident to us that exercising specific muscles results in an increase in that particular group of muscles. But what of brains and cognition? Is it really a case of 'use it or lose it'? What is neuroscience and how is this relevant to education? What can educators learn from a global perspective in educational neuroscience? What are the imaging methods used in neuroscience? How does the brain develop over the course of a lifetime? How is neuroscience of particular interest to science educators and teachers?

We are now many years on from the 'bridge too far' scenario by which Bruer (1997) meant that there was an unbridgeable gap between contemporary understandings from brain imaging and the mind models derived from cognitive psychology.

This paper has three purposes:

(1) to explore the current state of knowledge with respect to the recent findings in neuroscience, providing an overview of brain structure and terminology and the imaging techniques used in neuroscience;

(2) to bring attention to the range of neuroscience myths which pervade education. Claims of brain-based learning support a wide range of products for parents and teachers. Some of the myths are explored here; and

(3) finally, to offer suggestions to embrace recent findings from neuroscience about brain development and function. These findings have implications for educators, policy makers, teachers and researchers in education and neuroscience.

Neuroscience 'investigates the processes by which the brain learns and remembers, from the molecular and cellular levels right through to brain systems (e.g., the system of neural areas and pathways underpinning our ability to speak and comprehend language)' (Goswami, 2004, p. 1). In recent years, neuroscience has shed light on 'attention, stress, memory, exercise, sleep and music' (Carew \& Magsamen, 2010, p. 686). For example, a 15-month musical training is correlated with improvements in auditory and motor skills in early childhood (Hyde et al., 2009). Research in the field of educational neuroscience is being used to understand how the brain develops and functions, for example, in the diagnosis of neurological conditions that then allows for early remediation, shedding light on the reward system in the brain, the neural impact of ostracism as well the evaluation of intervention programmes.

Goswami (2006) called for the gulf between educators and neuroscientists to be bridged more effectively in the interest of children's education. Developmental psychology has long informed educational theory and constitutes required preparation for pre-service teachers, equipping us with insight into, for example, stages of child development, strategies for managing children's behaviour and language acquisition. Science educators might deliberate on students' misconceptions, cognitive and practical skills and curriculum development. Education and neuroscience come together when we consider learning: for what greater impact does learning have but upon the brain? Educational neuroscientists include educators, 
physiologists, anatomists, cognitive psychologists, imaging specialists and those with interest in learning and development. With the growth in research in education and neuroscience (Howard- Jones, 2007; OECD, 2007; PMSEIC, 2009), it is timely to reflect on the impact and possibilities neuroscience can bring to education. For science educators, it is an opportunity to consider the recent advances in the sciences of learning and how we might best engage with research findings in neuroscience.

First, we consider the techniques used in neuroscience and what sort of information is yielded using different methods. We then review the extent to which the new discipline of educational neuroscience has developed globally. Next, we provide a brief overview of the structure of the brain and how changes in the brain over a lifetime are associated with stimulation, socio-economic status and learning. We present evidence for the prevailing view of the determinants of intelligence, discuss working memory (WM) and consider the impact of cognitive stimulation programmes. We examine the misuse of neuroscientific findings in 'brain based' learning programs and suggest that (particularly) teachers of science bring a sense of rigour to examining the merit and efficacy of such programmes. Finally, we consider the potential for future research in educational neuroscience.

\section{Imaging tools}

Imaging uses a range of tools to measure the activity of the brain. Some of these are noninvasive, such as electroencephalographic (EEG) recordings. These use electrodes on the scalp to measure the electrical potentials over different parts of the head, generating an image of neuronal activity. More usefully, event related potentials (ERPs), extracted from EEG recordings, are the small changes in voltages measured in response to sensory or cognitive events. Event-related potentials are the variations in voltage that occur when someone is thinking or processing information. Using a hair net embedded with electrodes, the activity of brains can be observed as children undertake particular activities or tasks. Event-related potentials are most useful in studying both the timing and sequence of response during a task. Other imaging tools include magnetic resonance imaging (MRI) and positron emission tomography (PET). Both of these methods can be used to measure changes in blood flow in the brain and 'map' the brain. With PET, radioactively labelled molecules are injected into the blood and taken up by tissues and cells preferentially by those with higher metabolic demands. Because of the use of radioactive isotopes, there has been little reliance on PET in educational neuroscience.

Functional magnetic resonance imaging (fMRI) is a technique that highlights changes in region-specific brain metabolic activity via the blood oxygenated level dependant signal due to synaptic activity. Spatial resolution of fMRI offers the opportunity to establish networks in the brain associated with specific cognitive functions and 'identify a specific part of the brain which plays a key role in a given task' (Sżücs \& Goswami, 2007, p. 121). Cognitive demand results in increased neural activity and greater metabolic activity. We can measure this demand either directly (PET) or indirectly (fMRI) as blood flow through the brain is inferred to determine cognitive demand. A very 'efficient' brain might have a lower blood flow in response to a particular task.

Growth in neuroimaging studies has led to renewed understandings of the brain. Cognitive neuroscientists have developed a wealth of knowledge through use of association and disassociation studies. As a result, brain functions have been identified with specific areas or regions of the brain. Work with individuals with brain lesions or brain damage has helped establish just how closely or not cognitive functions and brain structures are related. Whist 
areas of the brain have long been associated with specific functions, such as language acquisition, PET has revealed that response to visual stimuli is complex relying on a network of neurons across the brain. Not all brain functions are so disparately distributed in the brain, for example, circadian rhythms are maintained by localised neurons in the brain. So the picture of the brain dominated by either an area or network focus can be over simple and conclusions drawn from them misleading for teachers (Varma \& Schwartz, 2008).

\section{Educational neuroscience: a global phenomenon}

In 1999, the Organisation for Economic Development (OECD) initiated a cross-disciplinary project 'Brain and Learning' and this has continued to support the dialogue between educators and neuroscientists. Some key messages to emerge from this international collaboration have been that:

(1) educational neuroscience is generating new knowledge to inform policy, curriculum and practice,

(2) brain research provides important neuroscientific evidence to support the broad aim of lifelong learning and

(3) adolescents have great cognitive ability or 'high horsepower' coupled with emotional lability or 'poor steering'. (OECD, 2007, p. 16)

Integrating education and neuroscience research has been leading to the formation of transdisciplinary work. In Australia, a recent report called for the establishment of Science of Learning Centres drawing on research from education, neuroscience, psychology, cognitive and social sciences (PMSEIC, 2010), although the recommendations are yet to be realised. In the USA, the American Educational Research Association hosts a webpage of resources for teachers, researchers and parents, which links to centres across the USA and UK offering programs, research papers and information about educational neuroscience (http://www.aerabrain-education.org/Resources/Resources.aspx). In Europe, the European Association or Research on Learning and Instruction promotes research and dissemination of educational neuroscience findings. The International Mind, Brain and Education Society (IMBES) was recently established to 'facilitate cross-cultural collaboration in biology, education and the cognitive and developmental sciences' (see http://www.imbes.org/). In fostering such collaborations and promoting this work, researchers from a range of disciplines can develop research questions, investigations and methodologies together. Rather than educational practice being informed by cognitive science, the aim is for a synergistic partnership between researchers and practitioners. Such transnational and cross-disciplinary collaborations augur well for meaningful and fruitful research to occur, where the learning experience is central to inquiry. One might argue that we are witnessing the birth of the science of learning.

Global interest in neuroscience and education has led to a number of collaborations across disciplines to seek new ways of understanding teaching and learning through the synergy of biology, cognitive sciences, psychology, neuroscience and pedagogy. Tantalising for educators, a spate of imaging studies has brought the field of neuroscience into our domain: what can these tell us about cognitive development in the course of a lifetime? How can recent developments in neuroscience inform us as educators? How can children who seem so lethargic in the classroom apply themselves to their games with so much enthusiasm?

(Howard-Jones, 2011).

\section{Brains, development and learning}


The brain, as the rest of the body, is bilaterally symmetrical, with each of the two halves, or hemispheres, controlling functions on the opposite side of the body and communicating with each other through the corpus callosum. The back of the brain houses the cerebellum, with most of the brain comprising the cerebrum. Covering the cerebrum is the cortex, 2-4 mm thick, highly folded and grey in appearance. The grey colour arises from the unmyelinated neurons, the cell bodies and their dendrites; below the surface of the cerebral cortex, white matter contains the myelinated axons of nerve cells and forms the bulk of the brain. The white colour arises from myelination of the axons, which carry nerve impulses into, within and out of the brain. Myelination, the fatty product of glial cells, increases the speed of transmission of the nerve impulses. As individuals mature, myelination occurs in a predictable pattern from the back of the brain to the front, so the last part of the brain to be functionally mature is the frontal lobe. Loss of myelin is associated with a range of neurological disorders, including multiple sclerosis. The cerebral cortex can be described spatially in terms of the lobes, each approximately associated with different functions. For example, the frontal lobe is associated with planning, problem solving; the parietal lobe with spatial processing; the occipital lobe with vision; the temporal lobe with learning and memory, within which the hippocampus is located. The hippocampus is one of the few parts of the brain which continues to undergo neurogenesis (produce new neurons) throughout life.

Received wisdom is that humans have a disproportionately large brain, although recent studies have shown that we have but a scaled up version of the primate brain in terms of cellular structure and that the numbers of neurons and non-neuronal (glial) cells are found in a one-to-one ratio (Azevedo et al., 2009). Cells in the brain are not uniformly distributed by mass, type or number as Table 1 shows: the proportion of neuronal and glial cells differs in different parts of the brain. Non-neuronal or glial cells are small, act locally to support, nourish, protect and produce myelin. So as the neurons grow in number and length, they are supported by an increase in number of glial cells. Yet the balance of the neuron:glial mass in the brain appears to be constant across species. Structurally, then, different parts of the brain 'look' rather distinct and it has been suggested that it is the large number of 'glial cells in the cerebral cortex that accounts for the expected increase in computational power of larger brains' (Herculano-Houzel, Mota, \& Lent, 2006, p.12142).

The newborn brain is metabolically demanding (Eppig, Fincher, \& Thornhill, 2010; Meltzoff, Kuhl, Movellan, \& Sejnowski, 2009) and the early years see rapid growth in both the number of neurons and complexity of the connections or synapses between them. During childhood, synapse formation (forming connections between neurons) is at its highest rate, as is synaptic pruning, where less-frequently used connections are removed. Undernourished children are reported to have smaller heads and brains and lower measured intelligence than their adequately nourished counterparts (Eppig et al., 2010), suggesting that optimal brain growth requires sufficient nutrition in the early years.

The brain undergoes changes over the course of a lifetime and is said to be 'plastic' in the sense that it can change in response to environmental stimuli. Maturation of the brain to achieve a more efficient organ is brought about 'through the weakening of short-range functional connections, and the integration of distant regions into functional networks, by strengthening of long-range functional connections' (Dosenbach et al., 2010, p. 1361). In adolescents, both synaptic pruning and myelination (to increase transmission speed of nerve impulses) occur to strengthen neural connections in the brain. 
Table 1. The proportion of neuron, non-neuronal cells in the cerebral cortex, cerebellum and rest of the brain.

\begin{tabular}{lccc}
\hline Part of brain & Mass (\%) & Neurons (\%) & $\begin{array}{c}\text { Non-neurons (glial } \\
\text { cells) }(\%)\end{array}$ \\
\hline Cerebral cortex & 81.8 & 19 & 71.9 \\
Cerebellum & 10.3 & 80.2 & 19 \\
Rest of brain & 7.8 & 0.8 & 9.1 \\
\hline
\end{tabular}

Source: Azevedo et al., 2009. Source: OECD, 2007, p. 40 (OECD Publishing, http://dx.doi.org/10.1787/9789264029132-en, reproduced with permission).

Brain glucose metabolism seems to follow the same pattern as synapse formation and pruning with brain glucose metabolism of twoyear- olds equalling adult brains and nine-year-olds having twice the adult rate of metabolism (Raichle, 2010). The synaptic pruning that occurs during adolescence is accompanied by a reduction in glucose metabolism (see Raichle [2010] for a review of brain biochemistry). Recent fMRI studies have shown that brain maturation follows a non-linear pattern of growth with an asymptotic shape, 'towards a maximum brain age of about 22 years' (Dosenbach et al., 2010, p. 1361), well into early adulthood and long after physical maturation.

With headlines citing the 'Marilyn Monroe' single neuron effect, whereby individual neurons responded to a particular image (Cerf et al., 2010) we might assume that brain mapping is nearing completion and that mind control is well understood. It is timely to remember, 'the connection between these structural changes and behavioural changes is only beginning to be elucidated' (Giedd, 2004, p. 83). Imaging studies can provide confirmatory evidence of behavioural changes. Piaget and Sternberg have both found that children's cognitive limitations impact on their ability to solve analogy problems. In a study comparing reasoning abilities (of analogy and semantic visual reasoning) in adults and children, Wright, Matlen, Baym, Ferrer, and Bunge (2008) showed that children made more errors on analogy than semantic and were slower on the semantic tests than adults. Magnetic resonance imaging data showed both increased and differential activation of children's brains whilst solving the analogy and semantic reasoning problems and that this was age dependent. These data support findings from established behavioural research about reasoning and age and a recent review has described the growth in reasoning during late adolescence and early adulthood, suggesting age-related improvement in reasoning reflects the recruitment of specific areas of the brain, the rostrolateral prefrontal cortex (Crone, 2009).

It is thought that the prefrontal cortex, long established for its development in humans, contributes the greatest predictive power about brain maturity and that this region is associated with cognitive control and reasoning (Dosenbach et al., 2010). This area of the brain has been subject to considerable evolutionary selection and is greatly increased in humans relative to other primates. Changes to the prefrontal cortex during adolescence may be the neurological basis for improvement in reasoning (Wright et al., 2008). Although brains lose neurons throughout adulthood, the hippocampus, long associated with long-term memory and learning, continues to generate neurons throughout life. Maguire et al. (2000) showed the result of 'learning the knowledge' on the brains of would-be-taxi drivers in London, in which adult brains were shown to respond to particular environmental demands. Draganski et al. $(2004,2006)$ found that as a result of learning to juggle over a three-month 
period, there were measurable changes to grey matter although ceasing to juggle saw a reversion to 'normal' brain anatomy, suggesting that anatomical changes and plasticity is dependent on stimulation. Plasticity comes at a cost, though, as there is not unlimited capacity: brains of the London taxi drivers showed an increase in grey matter volume in the posterior hippocampus (which was positively correlated with the number of years spent as experienced taxi drivers) and reduced grey matter elsewhere in the hippocampus (Maguire, Woollett, \& Spiers, 2006).

Studies showing the relationship between intelligence and sex, age-related differences in brain size, volume and distribution of white matter, cortical thickness during development continue to inform neuroscience (Shaw et al., 2006). Males, for example, show greater performance on spatial cognitive tasks and imaging confirms greater neuronal efficiency compared with females. By contrast, 'females seem to be more neuronally efficient during tasks of verbal reasoning' (Deary, Penke, \& Johnson, 2010, p. 209). So, males and females are indistinguishable in overall performance possible through recruiting different parts of the brain. And doing just that, engaging quite different neural networks happens during poststroke recovery, where plasticity enables re-learning of old skills. Long-term studies of cortical thickness during childhood show a 'negative correlation between intelligence and cortical thickness in early childhood . . to a positive one in late childhood' (Shaw et al., 2006, p. 676). More intelligent children, as determined by Weschler tests, seem to show 'a prolonged phase of cortical increase' (Shaw et al., 2006, p. 676) to a much greater extent than their peers, suggesting plasticity in structure and plasticity implies malleability. Intelligence differences in both children and adolescents have been attributed to 'similar areas of the cortex' (Karama et al., 2009, p. 152), suggesting the mechanism for cortical thickening is somehow correlated with intelligence. Brain efficiency varies: highly intelligent people seem to have highly efficient brains and the resting state is lower than less intelligent peers (Deary, Penke, \& Johnson, 2010). This suggests that resting-state imaging can yield useful data about brain efficiency and intelligence. Learning results in changes in the biological function of the brain through 'a shift in patterns of activity' as well as gross structural changes (HowardJones, 2008a, p. 365).

\section{The brain and intelligence: cogito ergo sum}

Our ability to function as humans is very much bound up with our capacity to reason, solve problems and negotiate our way through the myriad of day-to-day activities. General intelligence, ' $g$ ', is thought to underpin all manifestations of intelligence. A broad definition, agreed upon by a group of academics in 1997, is:

Intelligence is a very general capability that, among other things, involves the ability to reason, plan, solve problems, think abstractly, comprehend complex ideas, learn quickly and learn from experience. It is not merely book learning, a narrow academic skill, or test taking smarts. Rather, it reflects a broader and deeper capability for comprehending our surroundings - 'catching on', 'making sense' of things, or 'figuring out' what to do. Intelligence, so defined, can be measured, and intelligence tests measure it well. (Gottfredson 1997, as cited in Deary, Penke, \& Johnson, 2010, p. 201)

Globally, intelligence is context-dependent in that measured intelligence is correlated with measures such as infant mortality, school enrolment, illiteracy, agricultural labour and gross national product (Eppig et al., 2010). The use of intelligence tests, such as Raven's matrices or Piagetian reasoning tasks to determine different aspects of reasoning ability produce data 
that suggest performance are correlated and load onto a general factor, $g$. Neuroimaging studies have suggested that tasks (involving novel problem solving and abstract reasoning) which load heavily onto $g$, are associated with specific brain activations in the lateral frontal cortex (Duncan et al., 2000) rather than drawing on disparate brain regions. This is not to suggest that intelligence is located in a particular physical place, but that this region of the brain is causally activated during specific reasoning tasks.

There are many who caution against a reductionist approach to intelligence and warn of confusing correlation with causation when considering data generated from imaging studies (Sternberg, 2000). Indeed, attempting to locate the source of $g$ in the brain may not be productive at all. We could perhaps say that $g$ exists in the brain 'in the sense that diverse brain processes are correlated' (Plomin, 2003, p. 1) across a widely distributed but wellconnected network. The concept of $\mathrm{g}$ has been further expanded by considering two components, fluid $g f$, which depends on in the- moment processing, or reasoning ability and crystallised $g c$ considered to be intelligence-as-product, dependent on experience, acquired cultural and educational knowledge. Whilst intelligence tests load onto g, other variance arises from domain-specific tests (such as spatial, verbal) these individual components 'contribute a small amount of variance compared with $g$ and the specific test' (Deary et al., 2010 , p. 202). While $g f$ declines with age and frontal lobe damage, as do processing speed and memory, $g c$ appears to be more resilient to the vagaries of age.

Executive functions (EF) are processes that regulate and control thought and action with a strong association with the frontal lobes and performance in intelligence tests. Throughout adolescence, there is a marked improvement in EF, with greater mastery over thoughts and action, self-control and cognitive gains, although tempered by the exhibition of risk taking, for example (Crone, 2009). Indeed, the non-linear and complex changes in the regulation of emotion and social 'competence' in adolescence need to be more clearly understood (Crone, 2009). A twin study investigated three components of EF: updating (WM); shifting and inhibiting EF and intelligence using Raven's Progressive Matrices (a measure of reasoning); and a Wechsler's test (a measure of intelligence in adolescence and adulthood). Updating WM showed the strongest correlation with intelligence and given its role in attention, this is perhaps unsurprising (Friedman et al., 2006), although the widespread view is that $g$ and WM capacity are not the same entity (Bishop, Croucher, \& Duncan, 2008). General intelligence, then, seems to depend on more than good WM, speed of processing and educational opportunities, but nevertheless has some strong correlates with each of these.

Few cognitive training programs have been able to show long-term gains or transfer to other learning tasks (Owen et al., 2010). A recent study involved the training of WM and the impact of this training on $g f$ (Jaeggi, Buschkuehl, Jonides, \& Perrig, 2008) has shown that fluid intelligence can be improved by training WM; such improvement was dependent on the amount of training and observed across all levels of abilities and resulted from training WM in two distinct domains. The educational significance of such findings cannot be overlooked: intelligence is not fixed, is modifiable, and suggests that conventional intelligence tests provide 'indices that may be dynamic rather than fixed' (Sternberg, 2008, p. 6791), although this is not accepted by all (see Moody, 2009). It suggests for educators that, rather than limiting student achievement, WM and $g f$ are eminently amenable to change.

Standard intelligence tests are sometimes criticised by some researchers, pointing out that there is more to intelligence than can be assessed by tests such as those developed by Binet or Wechsler. For example, where is a test that can assess creativity to be found? And what of 
'practical' intelligence? The notion that discrete intelligences exist, which each require particular attention and are independent from each other has not been substantiated.

Nonetheless, Gardner's theory of multiple intelligences has permeated school textbooks, which address the variety of different intelligences through specific tasks or activities. There is no evidence to date of its efficacy or improvement in educational or learning outcomes for students. By contrast, in the currently accepted model of general intelligence in the field of psychology, $g$ is thought to underpin success across a range of different cognitive activities (Duncan et al., 2000). This accounts for the greatest variance in cognitive tests, $g$ is 'the source of most of the predictive power of cognitive tests and . . is the locus of most of the genetic variance' (Deary et al., 2010, p. 202). It may well be that a large number of genetic variants exert relatively small effects, although the field of molecular and quantitative genetics is yielding data on heritability of traits in the cognitive domain from dementia to reading disability (Plomin, 2003). This is not to support a deterministic view of intelligence or hark back to the days where intelligence was thought to be fixed, immutable. On top of this rather hazy picture that is now emerging of what constitutes intelligence and how this manifests in classrooms, recent research also reminds us of the role of motivation or other affective variables as predicted by the early pioneers of intelligence testing (Duckworth et al., 2011).

There is yet no consensus on locating genes for intelligence, although more is known about where development is different through disease, developmental delay or metabolic conditions. For example, the metabolic disorder phenylketonuria (PKU), left untreated can cause severe mental retardation associated with structural brain changes. A lifetime of a diet low in phenylalanine mitigates the effects of this autosomal recessive genetic condition. In essence, the amino acid, phenylalanine, accumulates and is not able to be metabolised to tyrosine. Tyrosine is important as a precursor of dopamine, a neurotransmitter which is important in WM performance (Klingberg et al., 2005). 'Off-diet' adults with PKU show a reduction in dopamine levels with concomitant reduction in processing speed as determined by the Weschler tests (Moyle, Fox, Bynevelt, Arthur, \& Burnett, 2006). The reduction in cognitive performance may be due to the effect phenylalanine has on myelination or directly on the dopamine, which impacts frontal lobe anatomy. The dopamine link is interesting for its association with reward-seeking and risk-taking behaviours (Crone, 2009) and certainly adds to the complexity of understanding brain changes, brain development and behaviour in adolescence.

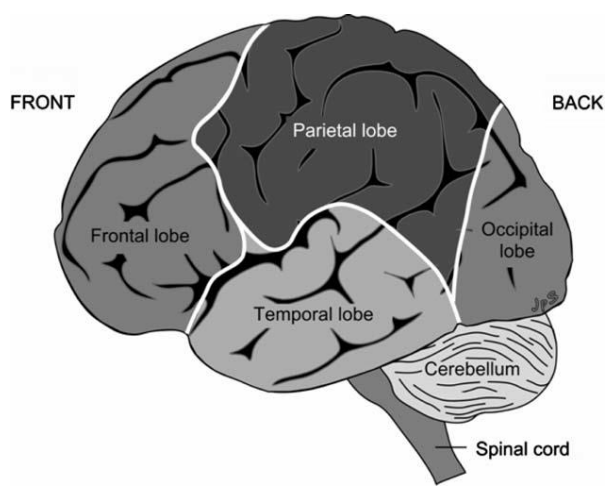

Figure 1. A diagram showing the major regions of the cerebral cortex. Source: Swanson, 1999. Source: OECD, 2007, p. 40 (OECD Publishing, http://dx.doi.org/10.1787/9789264029132-en, reproduced with permission). 
There is little data to support the claim that 'bigger is better' when it comes to brain function. Indeed, an inverse relationship exists between the hippocampal volume and memory for children (Van Petten, 2004). Gene studies suggest a correlation between brain structures, intelligence and brain size but the picture is complex: genetic influence on brain regions is not uniform throughout life or on different parts of the brain. For example, 'for white matter, genetic variance increased over time, whereas environmental variance increased for grey matter' (Deary et al., 2010, p. 205). More intelligent children, as determined by Weschler tests, seem to show 'a prolonged phase of cortical increase' (Shaw et al., 2006, p. 676) to a much greater extent than their less intelligent peers, suggesting plasticity in structure - and plasticity implies malleability. Intelligence differences in both children and adolescents have been attributed to 'similar areas of the cortex' (Karama et al., 2009, p. 152) suggesting the mechanism for cortical thickening is somehow correlated with intelligence. Evidence that there are neural differences between individuals of high and low IQ when reasoning has come from fMRI studies. Perfetti et al. (2009) investigated the effect of gf on reasoning using an adapted Raven's matrices task. As the task complexity increased, high IQ individuals showed greater activation in the pre-frontal cortex, whereas low IQ individuals showed decreased activity, whereas on a task of moderate difficulty, neural activation in low IQ individuals was much greater suggesting differential activation was IQ dependent. The mandate to "compare brain structure and activity in people with and without experience in solving cognitive tests' (Deary et al., 2010, p. 209) is likely to shed light on how intelligence develops and how this is manifest. Elucidating the neurological basis of drive, motivation and reward is in its infancy and possibly an area where teachers can engage directly with the 'what' and 'how' of future research.

\section{Working memory}

Working memory can variously be thought of as having two functions: as a temporary storage of information and manipulation of information and attention; or the keeping of 'momentarily relevant information in a stable, yet flexibly accessible state' (Bledowski, Kaiser, \& Rahm, 2010, p. 177). Various components of WM have been described such as visual, spatial and attention and are correlated with cognitive development; WM has a limited capacity that increases during childhood, reaching a peak at about 30 years and then declining thereafter (see Figure 2 and Swanson [1999] for detailed analysis of age-dependent WM).

It may well be that different parts of the brain are recruited in storage and manipulation of information. Conway and Getz (2008) confirm that WM training can lead to improved cognitive performance improvement (Klingberg, Forssberg, \& Westerberg, 2002; Klingberg et al., 2005) but raised questions about the constructs of WM, gf, gc, the neural mechanisms involved and the long-term effects of such training. Given that attention and WM are so closely linked, and that both are critical for learning, improving attention or WM may be subject to educational intervention. Few extant assessment tools in schools mean that children with poor WM often escape detection. Two such instruments have been described recently: the Automated Working Memory Assessment, a recently developed computerised tool with aged-related cut offs now enabling screening by teachers for schools (Alloway, Gathercole, Kirkwood, \& Elliott, 2008), and the Picture Span Test, which measures visual WM capacity (Tanabe \& Osaka, 2009) and it remains to be seen if they are robust instruments. Working with a small number of children with low WM, Holmes, Gathercole, and Dunning (2009), showed an improvement in WM and mathematical performance. 
An investigation into WM of both younger (20-30 years) and older (70-80 years) adults participated in a seven-week training programme based on the spatial n-back task, where $n$ is the number of stimuli to be recalled separately (see http://dual-n-back.com/nback.html for an example). The training programme was undertaken for 15 minutes per day by adults and results showed that both groups improved their performance on the practiced task, with near but no far transfer effects (Li et al., 2008). A three-month follow up showed that the younger adults were more likely to have maintained this compared with older aged participants. Even older people can benefit from training in WM: an extended training period of three months twice weekly yielded improvements in WM compared with an age matched control group (Buschkuehl et al., 2008), although this did not persist. Age-related changes to the striatum, a region of the forebrain interior, may well be responsible for the deterioration in performance in older adults and longitudinal studies investigating this part of the brain with imaging are likely to be informative. The lack of far transfer suggests that the intervention has been limited, although such evaluation of cognitive behaviour 'is methodologically difficult' (Klingberg, 2010, p. 318).

\section{Improving cognitive performance}

Even brief periods of training in mindfulness meditation (derived from Eastern traditions of meditation) have shown to be effective at improving cognitive function, with improved scores in tasks depending on attention and executive processing efficiency (Zeidan, Johnson, Diamond, David, \& Goolkasian, 2010).

Figure 2. Working memory changes over the course of a lifetime as measured by changes in visual-spatial capacity. Source: Swanson, 1999.

Mitigating the

onset of dementia is likely to have economic benefits and considerable effort is expended to maintain healthy older adults in the community. A five-year study of older adults examined the effects of a short intervention programme of 10 sessions on older adults. Participants were allotted to one of three intervention strategies which involved a specific sort of training - memory, reasoning and processing speed - with the finding that those given intervention in reasoning seemed protected against decline compared with participants in the other two groups (Willis et al., 2006). The data and findings on cognitive intervention are reported in medical and health literature and show that cognitive intervention programmes continue to be explored as possible therapeutic value to individuals (Busche, Bokde, \& Hampel, 2010). Cognitive intervention programmes clearly have their place in ameliorating the effects of cognitive decline in older adults, whether prophylactically or complementary to other regimes, but the same degree of rigour has yet to examine the merit of many 'brain-based' programmes in education.

Neuroscience confirms the role of intervention There exists a large body of well resourced educational and training packages claiming to support improvement in cognition, ameliorate cognitive decline in ageing and neurological illness and interventions to overcome learning difficulties. Claims about 'brain training' are often used in marketing and promotional literature, but not supported by empirical findings, despite their widespread use in schools 
(Stephenson, 2009). There is little evidence that 'brain training' games have a transfer effect, have a sustained impact or develop cognitive abilities in the general population (Owen et al., 2010). There may well be benefit ascribed to such training or cognitive testing, particularly in preventing cognitive decline in the ageing population, in stimulating the reward system in some individuals or for individuals with a neurocognitive condition (Amato et al., 2009).

Learning to read is of paramount importance in schools and yet between 5 and $17 \%$ of children experience difficulty that is not associated with defects in cognition, motivation or instruction (Gabrieli, 2009). In adults, a network involving the left hemisphere of the brain is thought to confer the ability to separate words into components of sounds. Dyslexia is thought to manifest itself from a neural processing impairment, where connectedness between different parts of the brain is reduced so making sense of reading is a challenge. Functional differences can be detected in newborns using ERPs and warrants further long-term investigation. At a functional level there appears to be reduced activation in the frontal and temporo-parietal regions of the brains of children and adults with dyslexia (Gabrieli, 2009). Schools often detect dyslexia on the basis of a mis-match in reading and general academic performance indicators. A number of studies have shown that computer training can assist in the remediation provided to children identified with dyslexia and many of these children seem able to overcome the initial difficulties experienced in learning to read, and imaging studies confirm changes in brain function. Intervention strategies that are intensive, directed and systematic to support remediation specifically target phonological awareness and decoding strategies are more effective in improving younger rather than older children (Gabrieli, 2009). The strong heritability of dyslexia and other neurodevelopment conditions suggests underlying genetic causes but to date only a few single-nucleotide polymorphisms 222 M. Oliver

Downloaded by [University of Western Australia] at 21:16 21 September 2011 have been located (Miller, 2005). With dyslexia being a recognisable obstacle to learning to read, it might be expected that children share a common brain signal and that this is not the case suggests a sensitivity to cultural influences (Grüter \& Carbon, 2010). Further investigations can shed light on whether there is a visual or linguistic basis for dyslexia. A likely scenario is that genetic, environmental and epigenetic effects may contribute to the condition, with perhaps, different genes increasing the susceptibility for dyslexia (Miller, 2005).

Dyscalculia presents in children with difficulties in calculating, perhaps even numerosity in general (Howard-Jones, 2007, p. 13) and, as for dyslexia, is independent of intellectual ability and schooling and has a lifelong economic, health and social impact. The acquisition of arithmetical facts is associated with a particular region of the brain, the intra-parietal sulci (IPS) and this area is found to be structurally different on dyscalculic children. Kaufmann et al.'s (2009) investigation was the first to compare neural correlates of children with and without dyscalculia when presented with a magnitude processing test. His team reported stronger activations in left (intra)parietal regions in dyscalculic children relative to controls and they suggested that 'the stronger recruitment of the left IPL observed in [the] group of dyscalculic children reflected ... compensatory mechanisms' (p. 5) to overcome the processing difficulties as well as drawing on a wider neural network to perform the task. Understanding dyscalculia will draw on both area and network models of the workings of the brain to explore possible diagnoses and remediation strategies (Butterworth, Varma, \& Laurillard, 2011; Kaufmann, 2008; Varma \& Schwartz, 2008). 
Establishing which areas or regions of the brain are involved in solving problems may help establish the neural basis for mathematical reasoning. For example, the role of using fingers in counting in developing early arithmetic skills has been confirmed by fMRI studies of children and adults: it seems that atypical brain mechanisms are correlated with deficiencies in using fingers to count (Kaufmann et al., 2008). Moreover, specific neurological correlations have been established with particular deficits in numerosity, comparison of number symbols and arithmetic. (Butterworth et al., 2011, p. 1051). These sorts of findings beg the question of neuroscience - is this just a (highly expensive) diagnostic tool? What more can be learned from neuroscience that traditional disciplines have been unable to teach us? Are there any practical and educational applications from the findings of neuroscience? How early can conditions such as dyscalculia be detected? What sort of effect does intervention have? We suggest that neuroscience and education together can foster the development of evidenced-based theories, to draw on what is known about genetics, imaging, child development and pedagogy. One such targeted intervention strategy in the classroom to support students in their early years of learning mathematics in Innsbruck (Kaufmann, Handl, \& Thöny, 2003) has specifically addressed basic conceptual and procedural knowledge, to good effect. The intervention over a six-month period, three times a week was a staged process of gradually developing numerical knowledge from the concrete to abstract resulting in greater proficiency in calculation skills. Another intervention recently reported using adaptive software informed by neuroscience and which targets the IPS may be helpful in overcoming the challenge of dyscalculia (Butterworth et al., 2011).

Other neuroimaging studies have centred on individuals with identified clinical conditions such as Attention-Deficit/Hyperactivity Disorder (ADHD) (Cherkasova \& Hechtman, 2009; Karch et al., 2010), autism (Ecker et al., 2010) and Alzheimer's disease (van der Hiele et al., 2007). Attention-Deficit/Hyperactivity Disorder has a Studies in Science Education 223

Downloaded by [University of Western Australia] at 21:16 21 September 2011 prevalence of about $5-10 \%$ of the population and is thought to result from executive function deficit, although there is a lack of uniformity in manifestation of the impairment (Lambek et al., 2010). Characterised by behavioural traits such as inattention, distractibility and hyperactivity, a closer study of the literature suggest that reward processing and regulation are also impaired (see Cherkasova \& Hechtman [2009] for a review of the studies). Lower academic performance in collegeaged students with ADHD and impaired WM, particularly the auditory component of a WM task, suggest that difficulties persist into adulthood (Gropper \& Tannock, 2009). A recent study using simultaneous EEG and fMRI has shown evidence of frontal brain functional deficits (Karch et al., 2010) although the data are generally inconsistent in establishing possible neural correlates. Remediating the effects of ADHD require educational interventions that address both behavioural and cognitive aspects, regardless of whether medication is also used.

Neuroscience confirms that socioeconomic status impacts cognitive development The construct of socioeconomic status (SES) is described elsewhere (Hackman \& Farah, 2009) and the effects of SES on health, educational and lifetime outcomes are well known. Recent findings from cognitive science have sought to address the mechanism by which SES positively impacts cognitive achievement from early childhood onwards (Hackman, Farah, \& Meaney, 2010; Evans \& Schamberg, 2009). A range of electrophysiological and imaging studies (EEG, ERPs and fMRI) confirm that SES correlates with brain function, 'modulating brain responses ... 
[and show] disparities in neurocognitive function ... with the prefrontal cortex' (Hackman \& Farah, 2009, p. 68) being involved in these disparities.

Whilst high-SES families can remediate low IQ, the limiting factor for low SES seems to be environmental influences. Early adversity seems to be amenable to enrichment through cognitive stimulation (Hackman et al., 2010, p. 656). Teacher quality has been shown to exert a powerful and long-term impact on students (Taylor, Roehrig, Hensler, Connor, \& Schatschneider, 2010) in 'moderating the genetic effects on early reading' (p. 512).

Teaching and learning science

Osborne and Dillon (2008) point out that 'the teaching of science is an established cultural practice passed on from one science teacher to another' (p. 22) and that it is difficult to change that culture quickly or easily. Many of our classrooms look as they did many years ago, with content-driven curriculum rather than pedagogy for developing understanding (Dillon, 2009). To find that college students in the USa and China have very similar reasoning abilities, although quite different performances on knowledge-based tests, suggests that the current state of assessment in many of the STEM subjects rely on content and recall at the expense of improved reasoning (Bao et al., 2009). 'Education' is traditionally thought of as a product of disciplines in social sciences as disparate as philosophy, sociology and psychology. This includes teaching and learning, applying both to what occurs inside and outside of classrooms settings. We educators tend to think of learning as something that students 'do' whilst engaged in the acquisition of knowledge, skills and behaviours to help inform and produce useful citizens.

224 M. Oliver

Downloaded by [University of Western Australia] at 21:16 21 September 2011 Learning or developing mastery is 'slow and hard' (Schwartz, 2009, p. 199), with effort having to be expended over years to become expert. In educational contexts, learning is computational, social and contextually driven. Few educational settings currently attend to the biological processes involved in learning, with one teacher asking, 'why should I be interested in the brain? I teach physics.' Across the globe, there are few teacher preparation programs in universities that include in their courses the biological basis of learning and we argue that this deficit be made good to include both teacher preparation and ongoing professional learning opportunities. Understanding the different philosophical bases of neuroscience and education needs to be reconciled, or at least clarified, so that discussion between educators and neuroscientists can be purposeful from classroom to educational policy level.

The measurement of learning in schools is either norm or criterion referenced. In both cases, we look for evidence that students have acquired particular knowledge or skills that are often described in a hierarchical structure, such as Blooms taxonomy. Recent evidence casts doubt on the assertion that testing only tests memory not understanding, with the hypothesis that the process of testing itself improves memory through using a mediator or cue that helps explicit scaffolding of ideas (Pyc \& Rawson, 2010). But in a classroom, where are the measurements of cognitive outcomes and how can they be usefully compared across different learning areas? How can we use questions in our classrooms that regularly extend thinking?

The more recently developed educational technologies have enabled a range of highly personalised learning opportunities which may 'improve access to those currently excluded from education in adulthood and in later life' (Royal Society, 2011, 
p. 9). The casual browser of the Internet can find within his/her reach, and for a small fee, a range of products that will stimulate, for example, cognitive growth, improve memory, reasoning and speed of processing. To this end, collaboration with the developers of digital technologies, educators in classrooms, learners and neuroscience may result in the critical evaluation and further development of technologies to promote learning.

Neuroscience paves the way for myths: a little learning can be a dangerous thing

Teachers are necessarily interested in the cognitive and other developments of the students they teach. Lack of knowledge about the biological basis of learning can be remedied through professional learning and teacher preparation. With the unparalleled growth in neuroscience research, the practical application of neuroscience findings in education seems to be currently occupied by highly marketed instead of evidence-based programmes (Stephenson, 2009) directed at improving cognitive performance. As well as playing a role in judicial matters, health management and policy, neuroscience can be 'a tool for science-based education policy, which can help assess the performance and impact of different educational approaches' (Royal Society, 2011, p. 9). We therefore suggest that educators at all levels consider how the findings from neuroscience can shed light on our practice (see Appendix).

Rather than wholeheartedly embracing or refuting claims made about the benefits of brain-based learning programs, we suggest that science teachers and science educators engage with neuroscience findings critically, scientifically and professionStudies in Science Education 225

Downloaded by [University of Western Australia] at 21:16 21 September 2011 ally. A number of myths have grown up around brains, some of which have permeated education.

These myths include, but are not limited to:

(1) There are critical periods of learning during which humans can develop cognitive reasoning particularly effectively (OECD, 2007).

(a) This may have its origins in studies of rats maintained in low stimulus environment, whose brains showed low synaptic density, or imprinting studies in young birds. The application to human from animal studies has been to suggest that enriched environments in the early years were essential to intellectual growth. Imaging studies have confirmed the plasticity of the brain with growth and pruning of synapses throughout life.

(b) No critical periods of learning have yet been found in humans. There may be sensitive rather than critical periods for learning and studies on very young children have shown that they are responsive to sounds produced by a variety of different language groups. This responsiveness is 'lost' unless the child hears the sounds regularly as part of his linguistic environment. Plasticity also means loss in response to lack of environmental cues.

(2) Individual students have specific learning styles, such as visual, spatial, kinaesthetic (VAK). Multiple intelligences (MI), 'Brain Gym'_(Stephenson, 2009) and learning styles (Crossland, 2008; Howard-Jones, Franey, Mashmoushi, \& Liao, 2009).

(a) The idea that individual students have specific learning styles, such as VAK, has currency in educational settings. A survey showed that $82 \%$ of pre-service teachers agree with the statement that, 'individuals learn better when they receive information in their preferred learning style' 
(Howard-Jones et al., 2009, p. 23).

(b) There is no evidence to date to support the claim of a preferred learning style and, even when the preferred learning style is used, no evidence of educational improvement.

(c) The prevalence of Brain Gym _, MI and VAK in schools calls into question the use of evidence in practice: are school administrators persuaded by a 'feel good' factor, anecdotal recommendations or the use of evidence-based research to determine educational programmes?

(3) Only about $10 \%$ of our brains are used at any time.

(a) This myth is often attributed to Einstein but more likely have found fame with the neurologists in the nineteenth century who found that only about $10 \%$ of neurons are active at any one time.

(b) Imaging studies have shown that brain activity is disparate and can be very 'precisely described' (OECD, 2007, p. 113). Phineas Gage himself survived a number of years following his accident, albeit with altered capacity. Indeed, localised areas damaged through injury, disease, strokes, can often result in considerable reduction in function.

(c) The brain is disproportionately demanding of the body's resources and when food is scarce, the impact on brain development is evident (Eppig, Fincher, \& Thornhill, 2010).

226 M. Oliver

Downloaded by [University of Western Australia] at 21:16 21 September 2011

(4) We are either right-brain or left-brain learners.

(a) The lateralisation of the brain into two hemispheres with identifiable functions has given rise to the popular myth that learners can be classified into right or left brain individuals. This is likely to have developed as a result of the work of Roger Sperry, awarded the 1981 Nobel Prize for the discoveries of functional specialisation of the cerebral hemispheres. Sperry (1968) reported that a split-brain individual behaved 'as if it had two separate brains - each with a mind of its own' (p. 296). Although the two hemispheres control different parts of the body and have discrete functions, both are employed and coordinate activities.

(b) When the two hemispheres are separated, there follows loss of function and capacity.

(c) Different activities employ different regions of the brain, which are task dependent rather than individual dependent. The over simplification of classifying people into left or right brain thinkers distracts from the reality of brain function: a network across different regions of the brain.

Other neuromyths that pervade everyday life are the need to drink eight glasses a day of water, the benefits of omega-3 supplements and the harmful effect of sugar. These claims have no evidence to substantiate them and this lack of evidence adds to the confusion for parents, students and all who care for children. Sylvan and Christodoulou (2010) provide an evaluative tool to assess the educational merit of brain-based learning products commercially available, cautioning that educational programmes need to be evidence-based, bring about measurable behavioural changes (which in usual terms might mean improved student behaviour, well being or achievement) and sustained impact. Neuroplasticity training programmes (Goswani, 2006) need to be scrutinised for efficacy and impact.

There is a need for studies to bring scientific evidence to evaluate educational interventional strategies (Howard-Jones, 2009) as well as bridge the education neuroscience 
divide that currently exists, in some places more than others. In this sense, the application of evidence-based practice could do for education for what it has achieved in medicine a century ago.

Implications for teachers and neuroscientists

Overcoming inequalities of birth and creating educational opportunities for more students is surely a driver of educational reform and practice, for 'we don't want talent to be dependent on who your parents are, or where you were born' (Benbow, 2010 as cited in Mervis, 2010, p. 1583). Research and developments in technology have enabled us to understand synaptic plasticity throughout life, suggesting causal correlations between brain structure, function and behaviours. Far from being reductionist, educational neuroscience seeks to bring together an understanding of the complexity that surrounds learning, from social, cognitive and neural levels, their interaction and effects.

Neuroscience is not a panacea for education; it cannot develop teaching strategies or direct teaching practice, nor can it offer strategies for teachers to better engage students in science classes. However, 'the science behind teaching strategies ... can help educators address the why of what they do' (Sylvan \& Christodoulou, 2010 , p. 1) and embed the practice of teaching in a new paradigm. In the context Studies in Science Education 227

Downloaded by [University of Western Australia] at 21:16 21 September 2011 of educational research, imaging studies may provide an insight into how we can best tap into the reward systems in students, to better engage them in learning, or the specific neurological structures that underlie complex cognitive process, such as abstract reasoning, which underpin the knowledge structures in science. For the near future, we might expect neuroscience to make contributions to educational practice at the level of behavioural studies, to 'support or falsify educational theories rather than derive them' (Devonshire \& Dommett, 2010, p. 354) and to provide evidence for, rather than develop educational theories and practice. The IMBES is well placed to champion such avenues of inquiry, to promote such collaborative practice, mindful that the evidence about learning will not emerge from neuroscience studies alone (OECD, 2007, p. 249). Neuroscience may shed light on questions such as 'how do children learn to associate letters and sounds?' when learning to read (McCandliss, 2010) but have little to offer the research into student readiness, motivation or autonomy in a science classroom. Clearly, as partners in the emerging cross-disciplinary research, teachers, parents and educators will want to address those sorts of questions.

We accept the premise that teaching and learning are 'intricately intertwined with brain function' (Carew \& Magsamen, 2010, p. 685) and argue that teachers need to be better equipped with knowledge about neuroscience and skills to help distinguish the science from non-science. Early exposure to the ideas in neuroscience for pre-service teachers is likely to be beneficial in guiding and forming their ideas about teaching and learning (Howard-Jones et al., 2009). Hence, this paper addresses science educators specifically, as science teachers are perhaps more expert than their colleagues to consider and evaluate evidential the claims of data generated through scientific investigation. While neuroscientists develop new perspectives on brain science, it will be teachers that are will be active in translating these findings into everyday practice in classrooms and schools.

Capitalising on what is known about research-based pedagogies to improve learning needs to be central to both pre-service and in-service professional learning. Disappointingly, 'much classroom practice appears to neglect what has been shown 
to be effective' (Royal Society, 2010, p. 83) in the teaching of science and mathematics in UK schools and there is no reason to suppose that this represents an isolated example. Why are teachers not using methods that have demonstrated best practice? Bringing about teacher change in pedagogy seems to be very challenging at an individual level and has policy implications for educational practice. Physics Nobel Laureate, Carl Wieman, has suggested that reducing the cognitive load (see Wieman [2007] for a clear illustration) by slowing down, minimising jargon and explicit structuring and 'chunking' of material reduces the cognitive load and helps students learn more deeply. For educators, the prospect of being able to support students in developing metacognitive skills is compelling and grounded in solid educational theoretical evidence (Higgins, Baumfield, \& Hall, 2007). The 'possibility of being able to "train" metacognitive ability by harnessing underlying neural plasticity' (Fleming, Weil, Nagy, Dolan, \& Rees, 2010, p. 1543) certainly has merit as best educational practice with considerable benefits to students' thinking. As science teachers and educators, perhaps it is up to us to embrace scientific insights more completely in our teaching and preparation of teachers and attend to the findings of neuroscience that are more frequently published in traditional science rather than educational journals, to develop a science of teaching and learning. There is enthusiasm for a closer partnership between neuroscientists and educators, 228 M. Oliver

Downloaded by [University of Western Australia] at 21:16 21 September 2011 though some uncertainty as to how this will develop (Pickering \& Howard-Jones, 2007). Such collaborations will need to be focused on improving educational practice and understanding the quite different disciplines that each bring to the other. We might reflect on some of the advances made in neuroscience that have already impacted educational opportunities and experiences; for example, the advent of cochlear implants has brought the experience of hearing to many deaf children. The need for educators and neuroscientists to work closely together has been highlighted in a recent review (Royal Society, 2011). As Kaufmann (2008) has succinctly summarised the argument that:

educational experts must share their expertise in pedagogy, and neuroscience researchers must develop ecological paradigms that are capable of investigating cognitive processes and learning mechanisms instead of circumscribed skills. (p. 168)

The collaboration between teachers and neuroscientists needs to address these issues:

_ What do educators need to know about the human brain, the neurology of learning?

- What insight can neuroscience bring to understanding and improving the learning process?

_ How can we use reward in our teaching and learning programmes?

_ Should teacher preparation and in-service courses include critical evaluation and distillation of research and 'brain based' programs? (Summak, Summak, \& Summak, 2010)

_ How may the trans-disciplinary vision of research be best fostered to inform and guide the practice of teaching and the experimental, diagnostic and evaluative work of neuroscience?

_ How do educators develop a sense of scientific scepticism to assess claims made about educational programs? (OECD, 2007)

_ What is the most effective way in which cross-disciplinary collaborations can best communicate with each other, conduct research and inform policy? 
What is the optimal timing for different forms of learning?

How do specific materials and environments shape learning? (OECD, 2007,

p. 6)

_ Given that literacy and numeracy play such important roles in literate cultures,

what role does the brain play in learning? (OECD, 2007, p. 6)

Understanding brain development can inform educational practice: the strongest

evidence for sensitive periods is in the development of sensory systems, so that language

and music learning 'skills are likely to be more effectively acquired if learning

commences in early schooling' (Thomas \& Knowland, 2009, p. 19). Learning

new skills continues throughout childhood, adolescence and adulthood and is

clearly dependent on more than sensitive periods of brain development. The relatively

new discipline of educational neuroscience draws from traditional sciences

and educators: an informed partnership to investigate, to research and to inform

interventions and educational practice. Science educators are well placed to champion

the cause for being scientific about teaching, embedding findings from neuroscience

in pre-service teacher courses and continued professional learning. It is

churlish to point out the discrepancy in funding for health and education, but per-

Studies in Science Education 229

Downloaded by [University of Western Australia] at 21:16 21 September 2011

haps a significant contribution to the science of learning will only eventuate with

greater financial support. Of course, 'neuroscience builds on the conclusions of existing knowledge and everyday observation but it's important contribution is in enabling the move from correlation to causation - understanding the mechanisms behind familiar patterns - to help identify effective solutions' (OECD, 2007, p. 5).

However, neuroscience itself is a new science and will doubtless raise new

questions to explore and science educators need to be involved at this juncture to

engage with the literature, the research findings and to set the research agenda.

Finally, knowing about synaptic plasticity gives us, as teachers, encouragement that

learning is possible for everyone: every student has the capacity to change their

brain (Dubinsky, 2010).

Notes on contributor

Mary Oliver is a science educator and researcher at the University of Western Australia. Her research activities focus on cognitive acceleration, educational neuroscience, mentoring and equity.

References

Alloway, T.P., Gathercole, S.E., Kirkwood, H.J., \& Elliott, J.E. (2008). Evaluating the validity of

the Automated Working Memory Assessment. Educational Psychology, 7, 725-234.

Amato, M.P., Goretti, B., Ghezzi, A., Lori, S., Zipoli, V., Portaccio, E. . . Trojano, M. (2009).

Cognitive and psychosocial features of childhood and juvenile MS. Neurology, 72(13), 11891190.

Azevedo, F.A.C., Carvalho, L.R.B., Grinberg, L.T., Farfel, J.M., Ferretti, R.E.L., Leite, R.E.P. . . .

Herculano-Houzel, S. (2009). Equal numbers of neuronal and nonneuronal cells make the human brain an isometrically scaled-up primate brain. Journal of Comparative Neurology, 513(5), 532-541.

Bao, L., Cai, T., Koenig, K., Fang, K., Han, J., \& Wang, J. . . Wu, N. (2009). Physics:

Learning

and scientific reasoning. Science, 323(5914), 586-587. 
Bishop, S.J., Fossella, J., Croucher, C.J., \& Duncan, J (2008). COMT val158met genotype affects

recruitment of neural mechanisms supporting fluid intelligence. Cerebral Cortex, 18(9), 2132-2140.

Bledowski, C., Kaiser, J., \& Rahm, B. (2010). Basic operations in working memory:

Contributions

from functional imaging studies. Behavioural Brain Research, 214(2), 172-179.

Bruer, J.T. (1997). Education and the brain: A bridge too far. Educational Researcher, 26(8), 4-16.

Busche, V., Bokde, A.L., \& Hampel, H. (2010). Cognitive intervention in Alzheimer disease. Nature

Reviews Neurology, 6(9), 508-517.

Buschkuehl, M., Jaeggi, S.M., Hutchison, S., Perrig-Chiello, P., Däpp, C., Müller, M. . .

Walter,

J. (2008). Impact of working memory training on memory performance in old-old adults.

Psychology and Aging, 23(4), 743-753.

Butterworth, B., Varma, S., \& Laurillard, D. (2011). Dyscalculia: From brain to education.

Science,

332(6033), 1049-1053.

Carew, T.J., \& Magsamen, S.H. (2010). Neuroscience and education: An ideal partnership for producing

evidence-based solutions to guide twenty-first century learning. Neuron, 67(5), 685-688.

Cerf, M., Thiruvengadam, N., Mormann, F., Kraskov, A., Quiroga, R.Q., Koch, C., \& Fried, I.

(2010). On-line, voluntary control of human temporal lobe neurons. Nature, 467(7319), 1104-1108.

Cherkasova, M.V., \& Hechtman, L. (2009). Neuroimaging in attention-deficit hyperactivity disorder:

Beyond the frontostriatal circuitry. Canadian Journal of Psychiatry, 54(10), 651-664.

Conway, A.R.A., \& Getz, S.J. (2010). Cognitive ability: Does working memory training enhance

intelligence? Current Biology, 20, 362-364.

Crone, E.A. (2009). Executive functions in adolescence: Inferences from brain and behavior.

Developmental Science, 12(6), 825-830.

Crossland, J. (2008). The myths surrounding 'brain-based' learning. School Science Review, 90

(330), 119-121.

230 M. Oliver

Downloaded by [University of Western Australia] at 21:16 21 September 2011

Deary, I.J., Penke, L., \& Johnson, W. (2010). The neuroscience of human intelligence differences.

Nature Reviews Neuroscience, 11, 201-211.

Devonshire, I., \& Dommett, E.J. (2010). Neuroscience: Viable applications in education?

Neuroscience

and Society, 16(4), 349-356.

Dillon, J. (2009). On scientific literacy and curriculum reform. International Journal of

Environmental

\& Science Education, 4(3), 201-213.

Dosenbach, N.U.F., Nardos, B., Cohen, A.L., Fair, D.A., Power, J.D., Church, J.A. . .

Schlaggar, 
B.L. (2010). Prediction of individual brain maturity using fMRI. Science, 329(5997), 13581361 .

Draganski, B., Gaser, C., Busch, V., Schuierer, G., Bogdahn, U., \& May, A. (2004).

Neuroplasticity:

Changes in grey matter induced by training. Nature, 427, 311-312.

Draganski, B., Gaser, C., Kempermann, G., Kuhn, H.G., Winkler, J., Büchel, C., \& May, A. (2006). Temporal and spatial dynamics of brain structure changes during extensive learning. Journal of Neuroscience, 26, 6314-6317.

Dubinsky, J.M. (2010). Neuroscience education for prekindergarten-12 teachers. Journal of Neuroscience,

30(24), 8057-8060.

Duckworth, A.L., Quinn, P.D., Lynam, D.R., Loeber, R., \& Stouthamer-Loeber, M. (2011).

Role

of test motivation in intelligence testing. Proceedings of the National Academy of Sciences, 108(19), 7716-7720.

Duncan, J., Seitz, R.J., Kolodny, J., Bor, D., Herzog, H., Ahmed, A. . . Emslie, H. (2000). A neural basis for general intelligence. Science, 289(5478), 457-460.

Ecker, C., Marquand, A., Mourao-Miranda, J., Johnston, P., Daly, E.M., Brammer, M.J. . . . Murphy,

D.G.M. (2010). Describing the brain in autism in five dimensions: Magnetic resonance imaging-assisted diagnosis of autism spectrum disorder using a multiparameter classification approach. Journal of Neuroscience, 30(32), 10612-10623.

Eppig, C., Fincher, C.L., \& Thornhill, R. (2010). Parasite prevalence and the worldwide distribution

of cognitive ability. Proceedings of the Royal Society, 277(1701), 3801-3808.

Evans, G.W., \& Schamberg, M.A. (2009). Childhood poverty, chronic stress, and adult working

memory. Proceedings of the National Academy of Sciences, 106(16), 6545-6549.

Fleming, S.M., Weil, R.S., Nagy, Z., Dolan, R.J., \& Rees, G. (2010). Relating introspective accuracy

to individual differences in brain structure. Science, 329(5998), 1541-1543.

Friedman, N.P., Miyake, A., Corley, R.P., Young, S.E., Defries, J.C., \& Hewitt, J.K. (2006).

Not

all executive functions are related to intelligence. Psychological Science, 17(2), 172-179.

Gabrieli, J.D.E. (2009). Dyslexia: A new synergy between education and cognitive neuroscience.

Science, 325(5938), 280-283.

Giedd, J.N. (2004). Structural magnetic resonance imaging of the adolescent brain. Annals of the

New York Academy of Sciences, 1021, 77-85.

Goswami, U. (2004). Neuroscience and education. British Journal of Educational

Psychology, 74,

$1-14$.

Goswami, U. (2006). Neuroscience and education: From research to practice? Nature

Reviews

Neuroscience, 7(5), 406-413.

Gropper, R., \& Tannock, R. (2009). A pilot study of working memory and academic achievement

in college students with ADHD. Journal of Attention Disorders, 12(6), 574-581.

Grüter, T., \& Carbon, C.-C. (2010). Escaping attention. Science, 328(5977), 435-436. 
Hackman, D.A., \& Farah, M.J. (2009). Socioeconomic status and the developing brain. Trends in

Cognitive Sciences, 13(2), 65-73.

Hackman, D.A., Farah, M.J., \& Meaney, M.J. (2010). Socioeconomic status and the brain:

Mechanistic

insights from human and animal research. Nature Reviews Neuroscience, 11(9), 651-

659.

Herculano-Houzel, S., Mota, B., \& Lent, R. (2006). Cellular scaling rules for rodent brains.

Proceedings

of the National Academy of Sciences, 103(32), 12138-12143.

Higgins, S., Baumfield, V., \& Hall, E. (2007). Learning skills and the development of learning

capabilities. London: EPPI-Centre, Social Science Research Unit, Institute of Education, University

of London. Retrieved December 18, 2010, from http://eppi.ioe.ac.uk/cms/Default.aspx? tabid $=1851$

Holmes, J., Gathercole, S.E., \& Dunning, D.L. (2009). Adaptive training leads to sustained enhancement of poor working memory in children. Developmental Science, 12(4), F9-F15. Howard-Jones, P. (2007). Neuroscience and education: Issues and opportunities. London: TLRP.

Studies in Science Education 231

Downloaded by [University of Western Australia] at 21:16 21 September 2011

Howard-Jones, P. (2008a). Philosophical challenges for researchers at the interface between neuroscience

and education. Journal of Philosophy of Education, 42(3-4), 361-380.

Howard-Jones, P. (2011). From brain scan to lesson plan. Psychologist, 24(2), 110-113.

Howard-Jones, P., Franey, L., Mashmoushi, R., \& Liao, Y.-C. (2009, September). The neuroscience

literacy of trainee teachers. Paper presented at the The British Educational Research Association Annual Conference, Manchester, UK.

Howard-Jones, P.A. (2009). Neuroscience, learning and technology (14-19), report for 14-19

Deep Learning Project, BECTA. Coventry: BECTA.

Hyde, K.L., Lerch, J., Norton, A., Forgeard, M., Winner, E., Evans, A.C., \& Schlaug, G. (2009).

Musical training shapes structural brain development. Journal of Neuroscience, 29(10), $3019-$

3025.

Jaeggi, S.M., Buschkuehl, M., Jonides, J., \& Perrig, W.J. (2008). Improving fluid intelligence with training on working memory. Proceedings of the National Academy of Sciences, 105 (19), 6829-6833.

Karama, S., Ad-Dab'bagh, Y., Haier, R.J., Deary, I.J., Lyttelton, O.C., Lepage, C.. . . Brain Development

Cooperative Group. (2009). Positive association between cognitive ability and cortical thickness in a representative US sample of healthy 6-18 year-olds. Intelligence, 37(2), 145155.

Karch, S., Thalmeier, T., Lutz, J., Cerovecki, A., Opgen-Rhein, M., Hock, B. . . Pogarell, C. (2010). Neural correlates (ERP/fMRI) of voluntary selection in adult ADHD patients.

European

Archives of Psychiatry and Clinical Neuroscience, 260(5), 427-440. 
Kaufmann, L. (2008). Dyscalculia: Neuroscience and education. Educational Research, $50(2)$, $163-175$.

Kaufmann, L., Handl, P., \& Thöny, B. (2003). Evaluation of a numeracy intervention program

focusing on basic numerical knowledge and conceptual knowledge: A pilot study. Journal of Learning Diabilities, 36(3), 564-573.

Kaufmann, L., Vogel, S., Starke, M., Kremser, C., Schocke, M., \& Wood, G. (2009).

Developmental

dyscalculia: compensatory mechanisms in left intraparietal regions in response to nonsymbolic

magnitudes. Behavioral and Brain Functions, 5(1), 35.

Kaufmann, L., Vogel, S., Wood, G., Kremser, C., Schocke, M., Zimmerhackl, L.B., \& Koten, $\mathrm{J}$.

W. (2008). A developmental fMRI study of nonsymbolic numerical and spatial processing.

Cortex, 44, 376-385.

Klingberg, T. (2010). Training and plasticity of working memory. Trends in Cognitive

Sciences,

14(7), 317-324.

Klingberg, T., Fernell, E., Olesen, P., Johnson, M., Gustafsson, P., Dahlström, K. . . .

Westerberg,

H. (2005). Computerized training of working memory in children with ADHD: A

randomized,

controlled trial. Journal of the American Academy of Child and Adolescent Psychiatry, 44(2), 177-186.

Klingberg, T., Forssberg, H., \& Westerberg, H. (2002). Training of working memory in children

with ADHD. Journal of Clinical and Experimental Neuropsychology, 24(6), 781-791.

Lambek, R., Tannock, R., Dalsgaard, S., Trillingsgaard, A., Damm, D., \& Thomsen, P. (2010).

Executive dysfunction in school-age children with ADHD. Journal of Attention Disorders,

21. Retrieved August 9, 2011, from http://www.ncbi.nlm.nih.gov/pubmed/20858784

Li, S.-C., Huxhold, O., Smith, J., Schmiedek, F., Lindenberger, Röcke C., \& Lindenberger, $\mathrm{U}$.

(2008). Working memory plasticity in old age: Practice gain, transfer, and maintenance.

Psychology

and Aging, 23(4), 731-742.

Maguire, E.A., Gadian, D.G., Johnsrude, I.S., Good, C.D., Ashburner, J., Frackowiak, R.S.J., $\&$

Frith, C.D. (2000). Navigation-related structural change in the hippocampi of taxi drivers. Proceedings of the National Academy of Sciences of the United States of America, 97(8), 4398-4403.

Maguire, E.A., Woollett, K., \& Spiers, H. (2006). London taxi drivers and bus drivers: A structural

MRI and neuropsychological analysis. Hippocampus, 10(12), 1091-1101.

McCandliss, B.D. (2010). Educational neuroscience: The early years. Proceedings of the

National

Academy of Sciences, 107(18), 8049-8050.

Meltzoff, A.N., Kuhl, P.K., Movellan, J., \& Sejnowski, T.J. (2009). Foundations for a new science 
of learning. Science, 325(5938), 284-288.

Mervis, J. (2010). A way to heal science education, but is there the political will? Science, 329 (5999), 1582-1583.

232 M. Oliver

Downloaded by [University of Western Australia] at 21:16 21 September 2011

Miller, G. (2005). Neuroscience: Genes that guide brain development linked to dyslexia. Science, $310(5749), 759$.

Moody, D.E. (2009). Can intelligence be increased by training on a task of working memory? Intelligence, 37(4), 327-328.

Moyle, J.J., Fox, A.M., Bynevelt, M., Arthur, M., \& Burnett, J.R. (2006). Event-related potentials

elicited during a visual go-nogo task in adults with phenylketonuria. Clinical

Neurophysiology,

117, 2154-2160.

O’Driscoll, K., \& Leach, J.P. (1998). 'No longer Gage': An iron bar through the head.' Early observations of personality change after injury to the prefrontal cortex. British Medical Journal,

317, 1673-1674.

OECD (Organisation for Economic Co-operation and Development). (2007). Understanding the

brain: The birth of a learning science. Paris: Author.

Osborne, J., \& Dillon, J. (2008). Science education in Europe: Critical reflections. London:

The

Nuffield Foundation.

Owen, A.M., Hampshire, A., Grahn, J.A., Stenton, R., Dajani, S., Burns, A.S. . . Ballard, C.G.

(2010). Putting brain training to the test. Nature, 465(1111), 775-778.

Perfetti, B., Saggino, A., Ferretti, A., Caulo, M., Romani, G.L., \& Onofrj, M. (2009).

Differential

patterns of cortical activation as a function of fluid reasoning complexity. Human Brain

Mapping,

30, 497-510.

Pickering, S.J., \& Howard-Jones, P. (2007). Educators' views on the role of neuroscience in education:

Findings from a study of UK and international perspectives. Mind, Brain, and Education, 1(3), 109-113.

Plomin, R. (2003). Genetics, genes, genomics and g. Molecular Psychiatry, 8(1), 1-5.

PMSEIC (The Prime Minister's Science, Engineering and Innovation Council). (2009).

Transforming

learning and the transmission of knowledge: Preparing a learning society for the

future. Retrieved 26 October, 2010, from

http://www.innovation.gov.au/Section/pmseic/Documents/

TransformingLearningEWGreportFINAL.pdf

PMSEIC (The Prime Minister's Science, Engineering and Innovation Council). (2010).

Impact

statement: Science of learning centres - preparing a learning society for the future. Retrieved

26 October, 2010, from

http://www.innovation.gov.au/Section/pmseic/Documents/FINALIMPACTSTATEMENT. 
pdf

Pyc, M.A., \& Rawson, K.A. (2010). Why testing improves memory: mediator effectiveness hypothesis. Science, 330(6002), 335.

Raichle, M.E. (2010). Two views of brain function. Trends in Cognitive Sciences, 14(4), 180-190.

Royal Society. (2010). State of the nation' report on 5-14 science and mathematics education. London: Author.

Royal Society. (2011). Brain waves module 2: Neuroscience: implications for education and lifelong

learning. London: Author.

Schwartz, M. (2009). Cognitive development and learning: analyzing the building of skills in classrooms. Mind, Brain, and Education, 3(4), 198-208.

Shaw, P., Greenstein, D., Lerch, J., Clasen, L., Lenroot, R., Gogtay, N. . . Giedd, J. (2006).

Intellectual

ability and cortical development in children and adolescents. Nature, 440(7084), 676-679.

Sperry, R.W. (1968). Mental unity following surgical disconnection of the cerebral

hemispheres.

The Harvey Lectures. Series 62, 293-323. New York: Academic Press.

Stephenson, J. (2009). Best practice? Advice provided to teachers about the use of brain gym

in Australian Schools. Australian Journal of Education, 53(2), 109-124.

Sternberg, R.J. (2000). The Holey Grail of intelligence. Science, 289(5478), 457-460.

Sternberg, R.J. (2008). Increasing fluid intelligence is possible after all. Proceedings of the

National Academy of Sciences, 105(19), 6791-6792.

Summak, M.S., Summak, A.E.G., \& Summak, P.S. (2010). Building the connection between mind, brain and educational practice; Roadblocks and some prospects. Procedia - Social and Behavioral Sciences, 2(2), 1644-1647.

Swanson, H.L. (1999). What develops in working memory? A life span perspective.

Developmental

Psychology, 35, 986-1000.

Sylvan, L.J., \& Christodoulou, J.A. (2010). Understanding the role of neuroscience in brain based

products: A guide for educators and consumers. Mind, Brain, and Education, 4(1), 1-7.

Sżücs, D., \& Goswami, U. (2007). Educational neuroscience: Defining a new discipline for the

study of mental representations. Mind, Brain, and Education, 1(3), 114-127.

Studies in Science Education 233

Downloaded by [University of Western Australia] at 21:16 21 September 2011

Tanabe, A., \& Osaka, N. (2009). Picture span test: Measuring visual working memory

capacity

involved in remembering and comprehension. Behavior Research Methods, 41(2), 309-317.

Taylor, J., Roehrig, A.D., Hensler, B.S., Connor, C.M., \& Schatschneider, C. (2010). Teacher quality moderates the genetic effects on early reading. Science, 328(5977), 512-514.

Thomas, M.S., \& Knowland, V.C. (2009). Sensitive periods in brain development:

Implications

for education policy. European Psychiatric Review, 2(1), 17-20.

van der Hiele, K., Vein, A.A., van der Welle, A., van der Grond, J., Westendorp, R.G., Bollen, E.

L., . . Middelkoop, H.A.M. (2007). EEG and MRI correlates of mild cognitive impairment and Alzheimer's disease. Neurobiology of Aging, 28(9), 1322-1329. 
Van Petten, C. (2004). Relationship between hippocampal volume and memory ability in healthy

individuals across the lifespan: Review and meta-analysis. Neuropsychologia, 42(10), 13941413.

Varma, S., \& Schwartz, D.L. (2008). How should educational neuroscience conceptualise the relation

between cognition and brain function? Mathematical reasoning as a network process

Educational Research, 50(2), 149-161.

Wieman, C. (2007). Why not try a scientific approach to science education? Change: The

Magazine

of Higher Learning, 39(5), 9-15.

Willis, S., Tennstedt, S., Marsiske, M., Ball, K., Elias, J., Koepke, K.M. . . . Wright, E. (2006).

Long-term effects of cognitive training on everyday functional outcomes in older adults.

Journal

of the American Medical Association, 296(23), 2852-2854.

Wright, S., Matlen, B., Baym, C., Ferrer, E., \& Bunge, S. (2008). Neural correlates of fluid reasoning

in children and adults. Frontiers in Human Neuroscience, 1(March), 8.

Zeidan, F., Johnson, S.K., Diamond, B.J., David, Z., \& Goolkasian, P. (2010). Mindfulness meditation

improves cognition: Evidence of brief mental training. Consciousness and Cognition, 19(2), 597-605.

234 M. Oliver

Downloaded by [University of Western Australia] at 21:16 21 September 2011

Appendix. Resources for educators

http://www.neuroeducational.net/ the Neuro Educational network at the Graduate School of Education,

University of Bristol, coordinated by Paul Howard-Jones. NEnet is a group of scientists, educational researchers and educators who are interested in issues at the interface of neuroscience and education. Lots of resources for educators, researchers.

http://brainu.org/ BrainU hosts a wide range of professional development resources and materials

for grades 5-12 science teachers.

http://education.jhu.edu/nei/ the Neuro-Education Initiative at John Hopkins University furthers

the understanding of how research findings from the cognitive and neurosciences has the potential to inform teaching and learning through research, collaboration and advocacy. http://www.gse.harvard.edu/academics/masters/mbe/ Harvard Graduate School of Education links

to information about master's programme in mind, brain, and education, designed for students

interested in connecting cognition, neuroscience and educational practice, especially involving learning, teaching and cognitive and emotional development.

http://www.cogmed.com/ Cogmed Working Memory Training is an evidence-based training programme

developed by Torkel Klingberg to improve attention in individuals.

http://www.humanconnectome.org/ The Human Connectome Project (HCP) funded by the

National Institute of Health in the US to map human brain circuitry in 1200 healthy adults 
using non-invasive neuroimaging. This project aims to generate knowledge about brain connectivity,

its relationship to behaviour, and the contributions of genetic and environmental factors to individual differences in brain circuitry.

http://faculty.washington.edu/chudler/neurok.html Neuroscience for Kids was awarded the 2010

Science Prize for Online Resources in Education and was established by Eric Chudler. http://thebrain.mcgill.ca/flash/index_d.html The Brain from Top to Bottom is an interactive website

about the brain and human behaviour, is available in French and English and each topic has three levels of complexity so suitable for a range of audiences.

http://www.aera-brain-education.org/Resources/Resources.aspx) Hosted by a Special Interest Group of the American Educational Research Association (AERA), the resources on the website update news on neuroscience, have links to organisations, website and educational programs and promote collaboration and understanding between education and neuroscience. http://dual-n-back.com/nback.html. There are examples of n-back tasks with a brief overview of

the rationale and testing.

Studies in Science Education 235

Downloaded by [University of Western Australia] at 21:16 21 September 2011 